\title{
Pharmacy education, workforce, practice, and sciences in Lebanon: Benchmarking with the FIP Development Goals
}

\author{
Hala Sacre ${ }^{1 *}$, Marwan Akel ${ }^{1,2^{*}}$, Rony M Zeenny ${ }^{3}$, Aline Hajj ${ }^{4,5}$, Souheil Hallit ${ }^{1,6}$, Pascale Salameh ${ }^{1,7,8}$ \\ ${ }^{1}$ INSPECT-LB: Institut National de Santé Publique, Épidémiologie Clinique et Toxicologie -Liban, Beirut, Lebanon \\ ${ }^{2}$ School of Pharmacy, Lebanese International University, Beirut, Lebanon \\ ${ }^{3}$ Clinical Pharmacy Department, American University Beirut Medical Center, Beirut, Lebanon \\ ${ }^{4}$ Laboratory of Pharmacology, Clinical Pharmacy and Drug Quality Control, Faculty of Pharmacy, Pôle Technologie-Santé (PTS), \\ Faculty of Pharmacy, Saint-Joseph University, Beirut, Lebanon \\ ${ }^{5}$ Faculty of Pharmacy, Saint-Joseph University, Beirut, Lebanon \\ ${ }^{6}$ Faculty of Medicine and Medical Sciences, Holy Spirit University of Kaslik (USEK), Jounieh, Lebanon \\ ${ }^{7}$ School of Medicine, University of Nicosia, Nicosia, Cyprus \\ ${ }^{8}$ Faculty of Pharmacy, Lebanese University, Hadat, Lebanon \\ *These authors contributed equally
}

\section{Keywords}

Developmental goals

Pharmacy education

Pharmacy practice

Pharmacy profession

Pharmacy research

Strategic planning

\section{Correspondence}

Souheil Hallit,

Faculty of Medicine and Medical Sciences Holy Spirit University of Kaslik (USEK)

Jounieh

Lebanon

souheilhallit@hotmail.com

\section{Marwan Akel}

School of Pharmacy

Lebanese International University

Beirut

Lebanon

marwan.akel@liu.edu.lb

\begin{abstract}
Background: In 2020, the International Pharmaceutical Federation (FIP) published a set of 21 global development goals (DGs) that bring together workforce/education [W], practice [P], and science $[\mathrm{S}]$ in a transformative framework, defining an improved and more advanced pharmacy profession for the next decade. This paper aims to benchmark the context of the Lebanese pharmacy profession with the respective elements of the FIP DGs to optimise the previously suggested strategic plan. Methods: A group of pharmacy researchers with extensive academic, professional, and post-educational experience endeavoured to map the FIP DGs with the work produced in Lebanon, describing the current situation. The documents mapped were sought from published literature and white papers developed by academia and the Order of Pharmacists of Lebanon (OPL), the national pharmacists' association. Results: This study found that efforts are necessary to bridge the gap between the current situation of the pharmacy profession in Lebanon and optimal practice. In the short term, existing projects should be immediately implemented, e.g. pharmacy curricula reforms and accreditation, postgraduate training, recognising pharmacy specialities, organising the profession, and assessing advanced competencies. In parallel, related policies and regulations should be updated. Cultural changes, involving closer ties between education and practice, are required to reform the pharmacy profession. In the medium term, a national research strategy, including earlycareer scientists mentoring and assessment tools validation, is necessary. Digitalising the patient profile and medication safety reporting and updating the pharmacists' database through appropriate platforms are also essential steps toward modernising pharmacy. Conclusion: Authorities and stakeholders should combine and coordinate efforts to implement existing plans and develop necessary strategies for optimizing pharmacy education, workforce, practice, and research, which is expected to bridge the gap between the challenging current situation of the profession in Lebanon and its optimal future development, for the best of the pharmacist and the patient's health.
\end{abstract}

\section{Background}

Over the past decades, scientific advances have led to the evolution of healthcare systems, with the emergence of patient-centred care and multidisciplinary teams to optimise health outcomes. Well-functioning and successful health systems are 
assumed to meet the needs and expectations of populations. These include improved health status, protection against health threats, equitable access to patient-centred care, and involving patients in decisions affecting their health (World Health Organization, 2010). Health systems should also be affordable (for patients and families, employers, and governments) and adaptable to new diseases, demographics changes, scientific discoveries, and dynamic technologies to be sustainable and remain viable (Fineberg, 2012). These attributes require leadership and governance, financial management, health information systems, access to essential medical products and technologies, and a well-performing workforce (World Health Organization, 2010).

Healthcare professionals are currently required to work within multidisciplinary teams, favouring interprofessional collaboration within and across settings to achieve optimal healthcare outcomes while reducing errors and costs. Their speciality, their roles have evolved and must adapt to current standards of care, which underpins reforms at both professional and educational levels (Green \& Johnson, 2015).

In particular, pharmacists' roles have long been studied and revised. The World Health Organization (WHO), in collaboration with the International Pharmaceutical Federation (FIP), had introduced the "nine-star pharmacist", adding new tasks to their scope of practice. Therefore, health education has to adapt to keep pace with these changes to avoid producing nonspecialized pharmacists, resulting in a mismatch of competencies to patient and population needs, disrupted collaborative work, and imbalances in the professional labour market (Frenk et al., 2010).

Lebanon is a developing country of the Eastern Mediterranean region, with a current severe complex crisis: financial, economic, political issues, the high number of foreign refugees, and the COVID-19 pandemic that is burdening an exhausted healthcare system (Sacre, Hallit, Hajj, \& Salameh, 2020). Health care authorities, such as the Ministry of Public Health (MOPH), have never adopted clear strategies related to the pharmacy profession, despite a comprehensive strategic plan based on evidence, including surveys and epidemiological studies, suggested by the national pharmacy association (Order of Pharmacists of Lebanon, OPL) (Hallit, Abou Selwan, \& Salameh, 2020). Many plans were not implemented because of political and organizational instabilities. The role of community pharmacists has recently expanded in urban areas due to a decreased buying power stemming from economic decay, which has led patients to save on medical consultations. Moreover, after the Beirut blast, as hospitals were overwhelmed and selecting their cases, community pharmacies have become referrals. This situation intensified with the regulation of influenza vaccines, where the MOPH has given the authority to the community pharmacist to select eligible patients; the administration of other vaccines by community pharmacists is being negotiated. Furthermore, the parliament recently decided to give the pharmacists liberty in selecting whether to switch to generics or not when dispensing prescription medication. All of these initiatives, added to the role played by pharmacists during the COVID-19 pandemic, have optimised the status of pharmacists in the community.

Nevertheless, policymakers should make more efforts to improve the profession and bridge the gap between the challenging Lebanese context and optimal practice. Recently, the International Pharmaceutical Federation (FIP) published a set of development goals (DGs) that can be used to benchmark the pharmacy profession in Lebanon. These 21 DGs bring together science, practice, workforce, and education in a transformative framework, defining an improved profession for the next decade (International Pharmaceutical Federation, 2021a).

The objective of this paper is to benchmark the context of the Lebanese pharmacy profession with the respective elements of the FIP DGs, regarding workforce and education [W], practice [P], and pharmaceutical sciences [S], to optimise the previously suggested strategic plan (Hallit, Abou Selwan, et al., 2020). This report can eventually be a starting point to optimise the profession at all levels; it serves as an assessment tool for needs, detects the gaps and areas of improvement, and highlights the strengths of the current situation.

\section{Methods}

\section{Mapping to FIP Developmental Goals}

The methods of this review were based on the developmental goals introduced by the FIP (Table I). A group of pharmacy researchers with extensive academic, professional, and post-educational experience endeavoured to map them with the work produced in Lebanon that describes the current situation. The documents mapped were sought from published literature and white papers developed by academia and the Order of Pharmacists of Lebanon (OPL). Published papers were retrieved from PubMed, using the following keywords: pharmacy profession, pharmacy education, pharmacy practice, pharmacy research, and Lebanon. All articles were checked for 
appropriateness and adequacy to be used in this work. White papers consisted of the documents developed and shared by the OPL (Order of Pharmacists of Lebanon, 2018a).

\section{Results}

\section{DG1- Academic capacity}

$D G 1[W]-$ In Lebanon, five pharmacy schools are approved and accredited by the Ministry of Education and Higher Education (MEHE). They offer a 5-year Bachelor of Science (B.S.) degree in pharmacy designed for entry-level pharmacists, with an optional additional year to earn a Doctor of Pharmacy (Pharm.D.). Some universities also offer master's degrees in pharmaceutical or medical sciences (Hallit, Abou Selwan, et al., 2020). The OPL has mapped the Lebanese workforce and projected the numbers through 2050; the results of this work confirmed that Lebanon has an oversupply of unspecialised pharmacists, with a shortage of specialised pharmacy workforce (Hallit, Sacre, Hajj, et al., 2019). Nevertheless, universities in Lebanon continue to admit and graduate pharmacist with no clear strategy.

Furthermore, a published study using OPL official figures showed that the "community" was the most common employment sector (63\%), followed by "pharmaceutical companies" (24\%) and "hospitals" (5\%). The high ratio of pharmacists to 10,000 populations (20.3) was contrasted by a low ratio of pharmacists per hospital and per 100 hospital beds (1.9 and 1.7, respectively). Surveyed pharmacists expressed their concerns about planning the supply, distribution, regulation, and professional scope of practice (Alameddine, Bou Karroum \& Hijazi, 2019).

Sequentially, the OPL developed a competency framework for Bachelor (BS pharmacy) and competencies for specialised pharmacists (Sacre, Hallit, Hajj, Zeenny, Akel, et al., 2020; Sacre, Hallit, Hajj, Zeenny, Raad, et al., 2020). It also launched the accreditation for pharmacy programs and suggested a complete accreditation guide for pharmacy schools in collaboration with the MEHE (Order of Pharmacists of Lebanon, 2018a). However, these projects are still waiting to be implemented by concerned authorities.

$D G 1[P]-$ The mapping of experiential education programs of the different schools showed discrepancies in preparing pharmacists for professional practice. Some universities have more communitybased training while others focus on clinical aspects; outpatients' clinics, industry, and pharmaceutical companies are also sites for training, with varying weights. Accordingly, the OPL issued clinical preceptors' competencies and recommendations to optimise training and leverage experiential education (Zeitoun et al., 2020). As for postgraduate experiential education, two universities offer pharmacy residency programs structured based on international recommendations (Hallit, Sacre, Zeenny, et al., 2019). In parallel, the OPL suggested laws related to the organisation of clinical and hospital pharmacy, in addition to credentialing and recognition of pharmacy specialities, to encourage pharmacists to engage in postgraduate education (Hallit, Sacre, Zeenny, et al., 2019).

DG1[S]- Pharmacy researchers assessed the needs of community pharmacies and hospitals to adapt them to pharmacy education (Hallit, Abou Selwan, et al., 2020; Iskandar et al., 2017); for example, in hospitals, frequent errors and medication safety problems require a change in pharmacy education and practice. The OPL has also suggested competencies for research pharmacists (Hallit, Hajj, Sacre, et al., 2019; Hallit, Sacre, \& Salameh, 2019) and promoted professional organisation engagement into research (Hallit, Hajj, Sacre, et al., 2019; Hallit, Sacre, \& Salameh, 2019). In parallel, educational institutions are developing postgraduate education programs, including professional (residency and professional master's degrees) and research (research master's degrees and Ph.D.) pathways, but without a clear workforce transformation strategy.

\section{DG2- Early career training strategy}

$D G 2[W]-$ No clear strategy is applied in Lebanon regarding early career training. The OPL worked on developing such a strategy and suggested a core competency framework for graduate (Sacre, Hallit, Hajj, Zeenny, Akel, et al., 2020) and postgraduate core training and additional advanced training before pharmacists can join the workforce (Sacre, Hallit, Hajj, Zeenny, Raad, et al., 2020). Pharmacists who select to undergo postgraduate education would benefit from a waiver of the suggested postgraduate training since the postgraduate education would be considered equivalent to the training.

$D G 2[P]-$ Early career training is expected to improve pharmacy practice. In parallel to educating the workforce through postgraduate training, pharmaceutical institutions should train early career pharmacists through a structured plan, including continuing education of practising preceptor pharmacists, certifying clinical preceptors (Zeitoun et al., 2020), and applying good pharmacy practice 
standards in all pharmacy fields (Badro, Sacre, Hallit, Amhaz, \& Salameh, 2020; Hallit, Sacre, Sarkis, et al., 2019).

DG2[S]- Early-career scientists should be mentored within educational and research institutions, as suggested in the pharmacy programs accreditation previously described (Order of Pharmacists of Lebanon, 2018a). Moreover, the OPL has been supporting students' organisations and young researchers by delivering research-based conferences and promoting soft skills and student-based activities (Hallit, Tawil, et al., 2020a; Sacre, Tawil, Hallit, Hajj, et al., 2019; Sacre, Tawil, Hallit, Sili, \& Salameh, 2019; Tawil, Hallit, Sacre, Hajj, \& Salameh, 2020).

\section{DG3- Quality assurance}

$D G 3[W]-$ The directors of undergraduate pharmacy education programs have undertaken accreditation endeavours, each according to their system (European or American). As such, the Saint-Joseph University (USJ) (Université Saint-Joseph, 2021) and the Lebanese University (LU) (Lebanese University, 2018a) follow CIDPHARMEF (Conférence Internationale des Doyens des facultés de Pharmacie d'Expression Française) and HCERES (Haut Conseil d'Evaluation de la Recherche et de l'Enseignement Supérieur). The Lebanese American University (LAU) (Lebanese American University, 2021b) and Lebanese International University (LIU) are accredited and certified, respectively, by the American College for Pharmacy Education (ACPE), while the Canadian Council accredits the Beirut Arab University (BAU) (Beirut Arab University, 2020a) for Accreditation of Pharmacy Programs (CCAPP). Moreover, the OPL collaborated with the Academic Board (which included faculty representatives from each university) and the MEHE to prepare a national accreditation project, expected to harmonize pharmacy education and adapt it to the local needs (Order of Pharmacists of Lebanon, 2018a); as stated above, this project has not been implemented yet.

$D G 3[P]-$ The national accreditation audit regularly conducted by the MOPH (Ministry of Public Health, 2019) evaluates pharmacy and laboratory services within hospitals. Regarding other pharmacy services, some sporadic research projects had assessed several aspects of pharmacy practice, such as Good Pharmacy Practice in community pharmacies (Badro et al., 2020; Hallit, Sacre, Sarkis, et al., 2019), including management, drug dispensing, and clinical services (Badro et al., 2020), in addition to continuing education (Sacre, Tawil, Hallit, Sili, et al., 2019), communication with patients (Hobeika, Hallit, et al., 2020), and knowledge, attitude, and practices regarding various chronic (Hallit, Zeidan, et al., 2020) and infectious diseases (Yaacoub et al., 2019). The results of these studies could feed into the quality assurance projects of pharmacy practice.

DG3[S]- Despite some activities related to quality and integrity in pharmaceutical research, development, manufacturing, and regulations to secure access to safe and effective products to the patient, more efforts are needed. The pharmaceutical industry and marketing representatives (Ministry of Public Health, 2021a) signed a code of ethics for drug distribution and promotion, stating that ethics committee approvals are mandatory in all hospitals where trials of new medications and other pharmaceutical research are conducted. Moreover, the MOPH developed and diffused lists of Non-Prescription drugs and generic substitution (Ministry of Public Health, 2021d). However, these lists need updating and enforcement. Also, the digitalisation of drug distribution needs further development and implementation to avoid falsification and smuggling (Ministry of Public Health, 2021c).

\section{DG4- Advanced and specialist development}

DG4[W]- Diverse training structures of heterogeneous quality are available for introductory and advanced experiential education. The OPL deployed efforts to homogenise postgraduate training (Sacre, Hallit, Hajj, Zeenny, Raad, et al., 2020), part of which was related to advanced experiential education. As for specialised training, they depend on the nature and field of the degree and vary according to the university and its type of accreditation, e.g. professional or research master's, residency training, Ph.D. in pharmaceutical sciences (with or without laboratory work).

$D G 4[P]$ - The postgraduate training elaborated and suggested by the OPL included educational outcomes frameworks and related activities (Sacre, Hallit, Hajj, Zeenny, Raad, et al., 2020). The OPL also proposed credentials recognition for specialised pharmacists, including hospital, clinical, community, research, industrial pharmacists, in addition to academic preceptors (Hallit, Sacre, Zeenny, et al., 2019). On the other hand, continuing education activities (general and specialized sessions, campaigns) are regularly held by the OPL (Hallit, Tawil, et al., 2020a; Sacre, Tawil, Hallit, Hajj, et al., 2019; Sacre, Tawil, Hallit, Sili, et al., 2019; Tawil et al., 2020) and academia, such as USJ (Université Saint-Joseph, 2014).

$D G 4[S]-$ Many research promotion activities are organised at academia and hospital levels, with sporadic recognition of research by the OPL. 
Recruitment and promotion of academics rely on research productivity, patents, fellowships, and grants. Some academic institutions also foster innovation and expertise. However, research promotion is not structured at the national level in the absence of a clear research strategy.

\section{DG5- Competency development}

DG5[W]- The OPL developed core competencies for non-specialised pharmacists in collaboration with academia. It also elaborated postgraduate (Sacre, Hallit, Hajj, Zeenny, Akel, et al., 2020) and advanced competencies (Sacre, Hallit, Hajj, Zeenny, Raad, et al., 2020) for the main fields of pharmacy, i.e. clinical, hospital, community, and industry. Leadership-related skills were included in different frameworks, according to their level of importance.

$D G 5[P]$-Some studies assessed core competencies and their determinants among graduates and practising pharmacists using a validated tool (Hajj, Hallit, et al., 2021; Zeenny et al., 2021). One study compared education systems, universities, degrees, and sociodemographic characteristics and found that graduates from universities adopting the American model and those holding a Pharm.D. degree, particularly fresh graduates, had a higher perception of competency in several axes, except for the public health aspect (Sacre, Hallit, Hajj, Zeenny, Akel, et al., 2020). Further studies are necessary to assess the advanced and specialised competencies of pharmacists.

DG5[S]- Competencies of researchers and preceptors were also developed (Hallit, Hajj, Sacre, et al., 2019; Hallit, Sacre, \& Salameh, 2019; Zeitoun et al., 2020). There is a need to validate assessment tools and apply them at all stages of the pharmacy profession.

\section{DG6- Leadership development}

DG6[W]- Leadership-related competencies were included in different frameworks, according to their level of importance. In addition to the introduction of leadership learning outcomes into all university curricula, several universities (Ramia, Salameh, Btaiche, \& Saad, 2016) regularly organised extracurricular activities, such as soft skills conferences, interprofessional education (IPE) encompassing leadership (Lebanese American University, 2021a), and United Nations (UN) initiatives for university students training on leadership.

$D G 6[P]-$ In recent years, the OPL scientific committee and university administrators organised several soft skills-related continuing education sessions (Order of Pharmacists of Lebanon, 2018a). However, pharmacists attending these activities were not formally assessed, but it is assumed that a gap exists, especially among older graduates. Continuing education for practising pharmacists should focus on teamwork and collaborative performance, responsibility, accountability, decision-making, and professional autonomy, to contribute to service development and align with local needs.

DG6[S]- The OPL assessed research motivation among practising pharmacists (Zeidan, Hallit, Zeenny, \& Salameh, 2019) and found that the majority would be willing to contribute to research but refrain due to lack of time and related education (non-specialised pharmacists have an insufficient education about research). The OPL also trained its staff pharmacists (working as inspectors) on how to collect data and contribute to ongoing research projects related to professional assessment and improvement. The objective was to create a network of community pharmacists for research, yet the plan was not implemented. However, at the national level, strategies to foster scientific leadership are still needed to promote excellence and innovation in pharmaceutical research, in addition to development, manufacturing, and regulations.

\section{DG7- Advancing integrated services}

$D G 7[W]-$ All university programmes have adopted modern pharmacists' competencies (local or international), founded on patient-centred and integrated health services for workforce development. These competencies also included social determinants of health and needs-based approaches, although more efforts are necessary at this level, as shown in the competencies assessment among pharmacy graduates (Zeenny et al., 2021).

$D G 7[P]$ - The OPL has included a people-centred and integrated health care provision in its vision based on an interprofessional and cross-setting continuum of professional services. Accordingly, it has developed an advanced patient e-profile linked to the physicianspharmacists-MOPH network (Domiati, Sacre, Lahoud, Sili, \& Salameh, 2018), allowing for medication therapy management and long-term follow up after prescription. However, this project requires the willingness and efforts of all stakeholders to be implemented. Moreover, the national primary care strategy should include pharmacists as essential players to decrease the burden on the healthcare system (Hallit, Abou Selwan, et al., 2020) by involving them in vaccination programs after thorough and appropriate training. 
DG7[S]- Based on the proposed patient e-profile, it will be possible to generate a big database, useful for scientific monitoring, evidence-based decision-making, and suggesting and testing new hypotheses (drug utilisation reviews) (Order of Pharmacists of Lebanon, 2018a). This e-profile database can further be helpful to assess professional services. However, more comprehensive strategies should encompass the promotion of research in all pharmacy sectors. All research fields (from fundamental to translational and clinical) should cover steps from gap assessment to implementation plans.

\section{DG8- Working with others}

DG8[W]-All universities have established some types of Interprofessional education (IPE) in their curriculum or extracurricular activities, such as the LU (multidisciplinary Master of Public Health) (Lebanese University, 2018b), LAU (mandatory co-curricular activities) (Lebanese American University, 2021a), USJ (mixed courses with physicians and dental practitioners) (Hajj, Azzo, et al., 2021; Hajj, Hallit, et al., 2019), in addition to the BAU (Beirut Arab University, 2020b) and the LIU (Lebanese International University, 2021). All pharmacy students are exposed to healthcare teams during their clinical rotations in different hospital units, constituting the principal interprofessional experience at the undergraduate levels (B.S. and Pharm.D.).

$D G 8[P]-$ At the practice level, some initiatives attempted to promote collaborative care: for example, the Lebanese Health Energy conference suggested legislation related to the improvement of several health professions, including pharmacy (Lebanese Health Energy, 2018). Moreover, an inter-ministerial committee discussed these legislations and tried to get them approved. Collaborative care assessment shows that interprofessional and interdisciplinary collaboration are still insufficient in the hospital and community settings (e.g. lack of clinical pharmacy and scarcity of collaboration between dentists, physicians, and pharmacists) (Mouhtadi et al., 2018); it also outlines that additional efforts are necessary to promote collaborative care.

DG8[S]- Most often, research related to public health and clinical pharmacy is interdisciplinary, particularly in hospital settings. Also, in the absence of a clear medication policy in Lebanon, access to medications and their quality are discussed within a multidisciplinary committee at the decision-making and governmental levels (Ministry of Public Health, 2021g), except for some sporadic decisions issued by the $\mathrm{MOPH}$, which are not part of a comprehensive strategy.

\section{DG9- Continuing professional development (CPD) strategies}

DG9[W]- In Lebanon, mandatory continuing education (CE) for pharmacists was implemented in January 2014 (Hallit, Tawil, et al., 2020a; Sacre, Tawil, Hallit, Hajj, et al., 2019; Sacre, Tawil, Hallit, Sili, et al., 2019; Tawil et al., 2020). Several institutions, such as the OPL and universities, started offering $C E$ activities to respective members and alumni. In the majority of cases, conferences and international congresses are organized in a collaborative spirit.

$D G 9[P]-$ Of all the registered practising pharmacists in Lebanon, $68.3 \%$ started their CE cycles, and $25.6 \%$ already completed the required credits. Among pharmacists enrolled in the CE system, the majority (69\%) used online courses at least once. Moreover, CE enrollment was similar among old and young pharmacists, except for newly registered. The majority of pharmacists preferred clinical and pharmacological topics, followed by preventive medicine and transferable skills. The main barriers to participating in CE sessions were work and family obligations, lack of interest, lack of time, and difficulties commuting and using technology. The OPL should develop strategies to motivate and enrol more pharmacists in the CE system while continuing to provide high quality and costfavourable CE programs to Lebanese pharmacists. Moreover, the collaboration between the OPL, academia and professional institutions can result in the implementation of field-oriented CPD (Sacre, Tawil, Hallit, Sili, et al., 2019).

DG9[S]- In the absence of a clear national pharmacyrelated research strategy in Lebanon, sporadic initiatives have been launched to improve professional development research. INSPECT-LB, an independent research group established in 2018, included a professional research axis in its structure (among other research fields) that addresses this matter and regularly conducts studies aiming to improve the pharmacy profession; these publications would serve to develop strategies related to the profession. INSPECT-LB also provides researchers and pharmacists with tools necessary for research, validated scales and quality checklists (INSPECT-LB, 2021). Moreover, INSPECT-LB researchers have validated several scales related to the profession, such as the Computer literacy scale for pharmacists (Hallit, Tawil, et al., 2020b) and the Lebanese Medication Adherence Scale (Bou Serhal et al., 2018; Ibrahim et al., 2020). 


\section{DG10- Equity and equality}

DG10[W]- There are no clear strategies in Lebanon addressing equity and diversity inequalities in pharmaceutical workforce development, CE and training, and career progression. However, all universities have admission procedures ensuring the selection of the most qualified students, regardless of other factors such as gender, age, or disability (Sacre, Hallit, Hajj, \& Salameh, 2020). The socioeconomic level of candidates affects their choice of a public or private university, noting the possible but limited financial aids and scholarships in private universities. Moreover, the OPL has included the protection of all pharmacists' rights in its mission (Sacre, Hallit, et al., 2019).

$D G 10[P]-$ There are no clear strategies for equity and diversity in pharmaceutical services delivery, service access, and service impact so that all people have access to quality pharmaceutical care. However, medications are included in the government strategy of universal health coverage; thus, people who cannot afford to buy their medications from community pharmacies are redirected to primary healthcare centres managed by the MOPH or non-governmental organizations (NGOs) (Ministry of Public Health, 2021f). Pharmacy students and practising pharmacists work in some of these centres and apply pharmaceutical care principles, although no formal assessment of the quality of services has ever been conducted.

DG10[S]- There is no evidence of a clear inclusive strategy for research in Lebanon; however, researchers in pharmaceutical sciences mainly reflect students' characteristics distribution. For example, female researchers are well represented; they participated in the FIP Women in Science and Education (WISE) group (International Pharmaceutical Federation, 2021b).

\section{DG11- Impact and outcomes}

DG11[W]- The pharmaceutical workforce has an impact on the improvement of health systems in Lebanon: according to the OPL, the majority of graduates (75$80 \%)$ practice pharmacy in different areas, which is expected to have an impact on patient health in Lebanon (Sacre, Hallit, et al., 2019).

$D G 11[P]$ - To date, the impact of pharmacists on patient health is not formally assessed. However, some sporadic studies (Akel et al., 2019; Hajj, Hallit, et al., 2019; Hajj, Hallit, Sacre, \& Salameh, 2018; Iskandar et al., 2017) that evaluated the role, knowledge, and patients' perception of pharmacists showed positive outcomes.

$D G 11[S]-$ Lebanon has rules and regulations regarding access to new medications, which are available through officially accredited importers, registered industrials, or university hospitals (Ministry of Public Health, 2021d). Pharmacists of different specialities are involved in these institutions and companies, although very few researchers work on developing new medications in Lebanese laboratories. Only in vitro (bioavailability comparison) and observational studies are carried out, while experimental, translational studies are scarce; moreover, no bioequivalence or pharmacokinetic studies are conducted due to the absence of specialised units (Sacre, Hallit, Hajj, \& Salameh, 2020).

\section{DG12- Pharmacy intelligence}

$D G 12[W]$ - There is no accurate data on the pharmacy workforce in Lebanon; even at the OPL, the national professional association where all practising pharmacists are registered, data about pharmacists is incomplete and needs regular updates. Hence, data on skill combinations, advanced and specialised needs, workforce capacity and practice, and related strategies rely on point prevalence studies conducted on samples of pharmacists or incompletely updated data (Alameddine et al., 2019; Hallit, Sacre, Hajj, et al., 2019).

$D G 12[P]$ - Efforts are urgent to update the data on pharmacists' workforce. Updated data will help in planning and implementing evidence-based service provision, development, and delivery. It will also direct policymaking and funding decisions.

DG12[S]- Although the Lebanese parliament recently approved the law on open data and the right to access information, pharmacist and medication databases need to be optimised and regularly monitored and updated to become useful. Access to data is expected to accelerate pharmaceutical research, development, manufacturing, and market approval of medical products, thus maximizing clinical benefits for individual patients.

\section{DG13- Policy development}

$D G 13[W]$ - In Lebanon, some laws and regulations apply to the pharmacy profession and the workforce at the individual level (Ministry of Public Health, 2021b). However, there is no well-defined or manageable strategy implementing a comprehensive needs-based development of the pharmaceutical workforce throughout the professional life cycle. This lack ties to the absence of a pharmacy intelligence database and clear needs assessment in pharmaceutical institutions.

$D G 13[P]-$ Despite obvious needs in some fields, including but not limiting to clinical pharmacy, the latter law has been lagging for more than eight years 
without being approved by the parliament. As for service implementation, integration, and remuneration, a tiny improvement has been accomplished. A fixed amount is allocated to the community pharmacist as a fee for service. However, pharmacy services are not yet acknowledged within broader national health policies.

$D G 13[S]$ - There is an obvious need to establish national pharmaceutical research strategies, which would define priorities regarding medication policies, intellectual property protection, and licensing. As for the pricing of medical products, it is under the authority of the MOPH. The price is referenced to that in the country of origin, seven European countries, and seven neighbouring countries.

\section{DG14- Medicines expertise}

DG14[W]- In Lebanon, pharmacists are educated to deliver quality medication expertise; based on related competencies, all pharmacy programmes prepare their students for this aspect of pharmacy practice, as found in different studies (Al-Hajje, Atoui, et al., 2012; Hajj, Hallit, Sacre, et al., 2018).

$D G 14[P]$ - Despite the absence of clear strategies in this regard, pharmacists in Lebanon are giving expert information and advice to patients, caregivers, health care professionals, and relevant agencies and stakeholders. They collaborate in medication safety improvement (Sacre, Hajj, et al., 2020), medication quality monitoring (Hobeika, Farhat, et al., 2020), and medication error surveillance (Al-Hajje, Awada, et al., 2012).

$D G 14[S]-$ Despite the absence of a research strategy, sporadic projects are carried out in academia and hospitals to provide science-based information on medications. Clinical studies in different fields of chronic and infectious diseases are frequently conducted, and disease management chapters are also written (The Order of Pharmacists of Lebanon Scientific Committee, 2018).

\section{DG15-People-centred care}

DG15[W]- In the absence of a national strategy, pharmaceutical education in Lebanon is patientoriented (clinical perspective) but not necessarily people-centred (public health perspective). Although many universities use a competency framework that emphasises the public health aspect, field assessment of graduates showed a gap at this level (Zeenny et al., 2021).

$D G 15[P]-$ In particular, practising pharmacists declared being competent in patient-centred care (therapeutic management). However, they admitted being less knowledgeable in public health aspects of prevention (screening, awareness campaigns, prevention, etc.) (Zeenny et al., 2021). Also, an assessment of the societal perspective showed that the general population is barely satisfied with pharmacists' services (Iskandar et al., 2017). Other studies reported lower empathy (Hobeika, Hallit, et al., 2020), burnout (Rahme et al., 2020), and low quality of life (Sacre, Obeid, et al., 2019) among pharmacists.

DG15[S]- Pharmacogenetic studies have addressed innovative personalised approaches to improve people-centred care in oncology, pain management, and psychiatry (Hajj, 2018; Hajj et al., 2017; Hajj, Khabbaz, Laplanche, \& Peoc'h, 2013; Hajj, Obeid, et al., 2019; Hajj et al., 2015); local guidelines were also issued regarding several infectious and chronic disease management (Doocy et al., 2017; Husni et al., 2017; Moghnieh et al., 2020). The extent to which the research results and guidelines are being applied in real life remains to be assessed (Kabbara, Meski, Ramadan, Maaliki, \& Salameh, 2018; Noubani, Nasreddine, Sibai, Tamim, \& Isma'eel, 2018; Haydar et al., 2019). Additionally, the OPL has issued guidelines for prescription and medication dispensing (Hajj et al., 2020).

\section{DG16- Communicable diseases}

$D G 16[W]-\quad$ Educational programmes emphasise communicable and vector-borne diseases at different levels and variable depth and breadth. Assessment studies show that pharmacists' knowledge of infectious diseases and antimicrobial resistance is variable, while their practice is not optimal or sometimes inappropriate (e.g. delivery of antibiotics without a prescription) (Salameh, Sacre, Hallit, \& Hajj, 2017; Zahreddine et al., 2018; Hallit, Zahreddine, Saleh, Shakaroun, \& Lahoud, 2020). Regarding emerging diseases, pharmacists are asking for guidance from relevant authorities for appropriate patient management and disease prevention measures (Zeenny et al., 2020).

$D G 16[P]-$ The participation of pharmacists in flu vaccination is noticeable in Lebanon. However, a national approach regarding their role in infectious diseases is lacking.

DG16[S]- The OPL conducted many projects to enable community and hospital pharmacists to monitor and respond to communicable diseases with innovative approaches for prevention and treatment, namely, the Lebanese advanced patient profile, an online platform to allow medication use review and medication therapy management (Domiati et al., 2018). 


\section{DG17- Antimicrobial stewardship}

DG17[W]- Similar to infectious diseases, antimicrobial stewardship is tackled with a variable emphasis in pharmacy programs. Some hospitals require that hospital and clinical pharmacists get certified to apply this concept in clinical settings.

$D G 17[P]-$ In some hospitals, the infection control module is mandatory for everyone working within their setting. Pharmacists are members of antimicrobial stewardship committees, effectively contributing to nosocomial infections prevention (Dimassi et al., 2018). As for community settings, the application of antibiotic stewardship is lacking (Zahreddine et al., 2018; Yaacoub et al., 2019; Hallit, Zahreddine, et al., 2020).

$D G 17[S]-$ Research in academia and some university hospitals is active and addresses antimicrobial resistance in the country (surveillance and innovative techniques), nosocomial infections determinants and outcomes, and animal/farm use of antibiotics (Salameh et al., 2017; Zahreddine et al., 2018; Yaacoub et al., 2019; Hallit, Zahreddine, et al., 2020).

\section{DG18-Access to medicines, devices \& services}

$D G 18[W]-$ Although some universities admit graduate fixed numbers of pharmacists, according to their logistical capacities (available training sites and laboratories), others are causing an oversupply of nonspecialised pharmacists in Lebanon (the highest ratio in the world) (Hallit, Sacre, Hajj, et al., 2019; Sacre, Hallit, et al., 2019). In parallel, specialised pharmacists lack within the workforce (Alameddine et al., 2019). However, no quantitative assessment has ever been done for market labour needs in Lebanon. Moreover, due to the severe socioeconomic crisis, some institutions/companies are dismissing working pharmacists, which could affect the quality of provided pharmaceutical services: this remains to be further assessed.

$D G 18[P]-$ This small country of five million inhabitants has a network of more than 3000 community pharmacies and more than 200 hospital pharmacists. The high ratio of pharmacists is increasing the risk of unfair competition within the challenging economic context. Smuggling, falsification, and low-quality medications are ongoing problems despite the hologram (created by the association of importers and supported by the MOPH) put on medication boxes to guarantee their quality and origin (Sholy \& Saliba, 2018). In addition to community pharmacies, universal medication coverage is secured through several means, including the network of MOPH dispensaries for chronic and primary health services, some NGOs, MOPH direct coverage, National Social Security Funds (NSSF), and other public third party payers (Ministry of Public Health, 2021f). It is noteworthy that the current financial and economic crisis is causing a shortage of medications and medical supplies, regardless of patient coverage; additionally, patients to be hospitalized are having a hard time getting admitted for similar reasons.

$D G 18[S]-$ Despite the lack of innovative drug development projects, all pharmacists have access to information about these new therapies, delivery systems, and manufacturing processes; however, their availability on the market is related to pharmaceutical companies.

\section{DG19- Patient safety}

DG19[W]- A pharmacovigilance system is currently being implemented within the Lebanese University in collaboration with the MOPH and the WHO (Ministry of Public Health, 2021e). However, academia is not yet involved and does not include courses dedicated to patient safety in their curricula. Efforts are needed to bridge this gap.

$D G 19[P]-$ Alongside its contribution to the pharmacovigilance system, which relies on notifications from healthcare professionals, the OPL conducted several activities to assess medication safety culture among pharmacists and the general population (Ramia, Zeenny, Hallit, Salameh, \& Order of Pharmacists Scientific Committee - Medication Safety, 2017; Akel et al., 2019; Hajj, Hallit, Ramia, Salameh, \& Order of Pharmacists Scientific Committee - Medication Safety, 2018; Hallit, Hajj, Shuhaiber, et al., 2019; Ramia, Zeenny, Hallit, \& Salameh, 2021). It also developed an adverse drug event (ADE) online reporting platform and offered several continuing education sessions and workshops about medication safety (Order of Pharmacists of Lebanon, 2018a, 2018b). Furthermore, Lebanese pharmacists contributed to the FIP Harm Reduction report (Mansur, 2016).

$D G 19[S]-$ A poison centre run by pharmaciststoxicologists is available within the USJ. It serves the general population and healthcare professionals across Lebanon (Université Saint-Joseph). Furthermore, several research projects related to medication safety and risk management are regularly conducted (Ramia et al., 2017; Hajj, Hallit, Ramia \& Salameh, 2018; Hallit, Hajj, Shuhaiber et al., 2019; Akel et al., 2019).

\section{DG20- Digital health}

$D G 20[W]$ - There is no national strategy for the digital transformation of the pharmacy workforce and effective processes to facilitate the development of digitally literate pharmacists. However, the COVID-19 
pandemic has expedited the conversion of education and learning to digital methods (Center for Educational Research and Development (CRDP), 2021); the assessment of the outcome is yet to be conducted.

$D G 20[P]-$ Several software systems are available at the community (point of sale programs) and the hospital levels (patients' files management); moreover, the OPL has suggested several advances in this field, such as the implementation of electronic prescriptions, the Lebanese advanced patient profile for therapy management, linked to a medication safety platform, in addition to a drug storage platform (Sacre, Hallit, et al., 2019). The implementation of these programmes was delayed for political reasons, despite their importance in optimising patient care in Lebanon. It is noteworthy that telepharmacy, a common practice in some countries due to the COVID-19 pandemic, is still not applied in Lebanon; this issue needs to be addressed and its legal framework organised.

DG20[S]- The MOPH is working on a barcoding system that helps in medication tracing for good storage and distribution practices, which is expected to contribute to healthcare delivery (Ministry of Public Health, 2014). As for innovative medical products using digital technology, this is part of novelties in the pharmaceutical industry sector (Blominvest Bank, 2018). Publications about this matter are not available.

\section{DG21- Sustainability in pharmacy}

DG21[W]- The problem of oversupply of non-specialised pharmacists and lack of specialised pharmacists has been well described, and its perpetuation would jeopardize the sustainability of the profession in Lebanon (Hallit, Sacre, Hajj, et al., 2019; Sacre, Hallit, et al., 2019). Consequently, a national strategy with governance solutions is necessary to organise the workforce supply by academic institutions and conciliate program learning outcomes with professional competency frameworks at the B.S., Pharm.D., and specialised levels.

DG21[P]- Pharmacy practice in Lebanon faces economic and financial difficulties (despite small breakthroughs in this regard), reflecting the Lebanese context and leading to pharmacists' dissatisfaction (Hallit, Zeenny, Sili, \& Salameh, 2017), burnout (Rahme et al., 2020), lower empathy towards patients (Hobeika, Hallit, et al., 2020), and reduced quality of life (Sacre, Obeid, et al., 2019), all expected to lower service quality and decrease professional sustainability on the long run.

$D G 21[S]-$ A clear strategy regarding the chemical and biological effects of medications on the environment is absent in a country overwhelmed with a chronic garbage crisis (Hashem, 2016). Hospitals and industries are still struggling to find ways to dispose of expired medications using safe methods of waste management (Arcenciel, 2014). Nevertheless, some pharmacists have adopted the personal initiative of Green Pharmacy (Toma \& Crişan, 2018).

\section{Suggestions to scale up the pharmacy profession in Lebanon}

Many already developed projects need to be implemented by relevant authorities in the short run to bridge the gap between the current situation and the FIP developmental goals. Further comprehensive strategies need to be elaborated for the medium and long term (Table I).

\section{Discussion}

Our results show that tremendous efforts are necessary to bridge the gap between the current situation of the pharmacy profession in Lebanon and optimal practice. In the short term, existing projects should be immediately implemented, e.g. pharmacy curricula reforms and accreditation, postgraduate training, recognizing pharmacy specialities, organising the profession, and assessing advanced competencies. In parallel, related policies and regulations should be updated. Thus, culture changes involving closer ties between education and practice are required to reform the pharmacy profession (Thibault, 2013). Additionally, digitalizing the patient profile and medication safety reporting and updating the pharmacists' database through appropriate platforms are essential steps toward modernising pharmacy (Patidar, Vinchurkar, \& Balekar, 2018).

Based on the work detailed above, at the level of the three longitudinal themes running across all the goals (pharmacy education, practice, and research), stakeholders should join efforts and organize strategic workshops in the medium term to develop comprehensive strategies. Decisionmakers, professional organisations, and academia should think together about the future of pharmacy within the healthcare system and set priorities to bridge the gap between the current situation and future goals.

As in other developing countries (Higher Education Council; Ministry for Education and Employment- Malta, 2020), it is suggested to plan a national research strategy, including early-career scientists mentoring and assessment tools validation (competencies and impact). A strategic vision, including continuous professional development fostering leadership and expertise according to specialities, comprehensive strategies of communicable and chronic diseases, and a medication quality assurance system, is also necessary to improve practice (Alomi, 2017; Rough, 2021). 
Table I: Roadmap for implementing FIP DGs in Lebanon

\begin{tabular}{|c|c|c|c|}
\hline Goal & Project & $\begin{array}{c}\text { Statu } \\
\mathrm{S}\end{array}$ & $\begin{array}{c}\text { Ter } \\
\mathbf{m}\end{array}$ \\
\hline DG1-Academic Capacity & Pharmacy programs accreditation project & 1 & ST \\
\hline \multirow{2}{*}{ DG2- Early Career Training Strategy } & Postgraduate training project & 1 & ST \\
\hline & Early-career scientists mentoring & $\mathrm{D}$ & MT \\
\hline DG3- Quality Assurance & Medication quality assurance comprehensive strategy & $\mathrm{D}$ & MT \\
\hline \multirow{2}{*}{ DG4- Advanced \& Specialist Development } & Pharmacy specialties strategy & 1 & ST \\
\hline & National research strategy & $\mathrm{D}$ & MT \\
\hline \multirow{2}{*}{ DG5- Competency Development } & Advanced and specialized competencies assessment & 1 & ST \\
\hline & Validation of competencies assessment tools & $\mathrm{D}$ & MT \\
\hline DG6- Leadership Development & Leadership fostering strategies & $\mathrm{D}$ & MT \\
\hline DG7- Advancing Integrated Services & A digital patient profile project & 1 & ST \\
\hline DG8- Working with Others & Interprofessional collaboration agreement & $\mathrm{D}$ & MT \\
\hline $\begin{array}{l}\text { DG9- Continuing Professional Development } \\
\text { Strategies }\end{array}$ & Continuous professional development strategy according to specialties & $\mathrm{D}$ & MT \\
\hline DG10- Equity \& Equality & $\begin{array}{l}\text { Strategy for equity and diversity in pharmaceutical services and } \\
\text { research }\end{array}$ & $\mathrm{D}$ & MT \\
\hline \multirow{2}{*}{ DG11- Impact \& Outcomes } & A formal assessment of pharmacists' impact and outcomes & $\mathrm{D}$ & MT \\
\hline & Innovation in research & $\mathrm{D}$ & LT \\
\hline DG12- Pharmacy Intelligence & Pharmacy workforce database updating & 1 & ST \\
\hline DG13- Policy Development & Policies to be developed and implemented for all strategies & D \& I & ST \\
\hline DG14- Medicines expertise & Strategy to promote medicines expertise by pharmacists & $\mathrm{D}$ & MT \\
\hline DG15- People-Centered Care & Include population health aspect in pharmaceutical education & 1 & ST \\
\hline \multirow[t]{2}{*}{ DG16-Communicable Diseases } & $\begin{array}{l}\text { Guidance on appropriate infectious disease management by } \\
\text { pharmacists }\end{array}$ & $\mathrm{D}$ & MT \\
\hline & Policy about involvement of pharmacists in vaccination & $\mathrm{D}$ & MT \\
\hline DG17- Antimicrobial Stewardship & $\begin{array}{l}\text { Policy on antibiotic use and stewardship in community and hospital } \\
\text { settings }\end{array}$ & $D \& I$ & MT \\
\hline \multirow{3}{*}{ DG18- Access to Medicines, Devices \& Services } & Market labour needs assessment & $\mathrm{D}$ & MT \\
\hline & Innovative drug development projects & $\mathrm{D}$ & LT \\
\hline & Tele-Pharmacy policy discussion & $\mathrm{D}$ & $\mathrm{LT}$ \\
\hline \multirow{2}{*}{ DG19- Patient Safety } & Integrate patient safety aspect in curricula and continuing education & $\mathrm{D}$ & ST \\
\hline & Pharmacovigilance system & 1 & MT \\
\hline \multirow{3}{*}{ DG20- Digital Health } & Digital transformation of the workforce & $\mathrm{D}$ & MT \\
\hline & Digital platforms & 1 & ST \\
\hline & Innovations in pharmaceutical sector & $\mathrm{D}$ & LT \\
\hline \multirow[b]{2}{*}{ DG21- Sustainability in Pharmacy } & Pharmacy sustainability strategy & $\mathrm{D}$ & MT \\
\hline & $\begin{array}{l}\text { Strategy on chemical and biological medication effects on the } \\
\text { environment }\end{array}$ & $\mathrm{D}$ & LT \\
\hline
\end{tabular}

Digital transformation, integrating equity and diversity principles into education and practice, and planning for pharmacy sustainability, are required for the workforce. It is noteworthy that applying these strategies to pharmacy alone will not be useful: successful health systems should be integrative, involving all health professions and institutions, and stemming from comprehensive national plans. Previous research has determined ten principles for integration, including but not limited to governance, patient focus, universal accessibility, leadership, and comprehensive services across the continuum of care (Suter et al., 2009). An explicit interprofessional collaboration agreement is the principal pillar of this concept, as ill-defined interprofessional collaboration might result in unhealthy rivalry and conflicts, thereby disrupting the functioning of the system (Badejo et al., 2020).

Moreover, the COVID-19 outbreak unveiled the vulnerability of health systems worldwide, overwhelming them and causing more casualties (Coccolini et al., 2020). Thus, it is warranted to develop plans for emergencies and crisis management and train health professionals to secure their readiness, particularly pharmacists (Aburas \& Alshammari, 2020). Measures should also include digital teaching and learning, in addition to telehealth practices, particularly telepharmacy. In the long term, there is also a need to innovate in research (drug development and pharmaceutical technologies) and to put in place 
policies related to telepharmacy and environmental aspects of medication use. Laws and regulations should be revised to include clauses about national catastrophes.

Finally, applying some principles linked to success is suggested, as shown in a paper assessing health systems from 60 countries: the 'acorn-to-oak tree' principle (a small scale initiative that can lead to system-wide reforms); the 'data-to-information-tointelligence' principle (the role of IT and data are becoming more critical for delivering efficient and appropriate care, but must be converted into useful intelligence); the 'many-hands' principle (concerted action between stakeholders is pivotal); and the 'patient-as-the-pre-eminent-player' principle (placing patients at the centre of reform designs is critical for success) (Braithwaite et al., 2017).

This work has several limitations, mainly related to the methods used in data collection, which may cause an information bias. Despite this limitation, this report is closer to the reality of the profession, given that the authors had themselves a major role in drafting all of the professional association (OPL) related projects and publications. Thus, it can be a template for other countries to assess their work: alignment of pharmacy with FIP DGs can be comparable to the alignment of the world with the sustainable development goals (SDGs) of the United Nations (UN). In addition, the needs being heterogeneous between the world regions. This report would allow further regional needs assessment by relevant authorities, namely the FIP.

\section{Conclusion}

Authorities and stakeholders should combine and coordinate efforts to implement existing plans and develop necessary strategies for optimising pharmacy education, workforce, practice, and research, which is expected to bridge the gap between the challenging current situation of the profession in Lebanon and its optimal future development.

\section{List of abbreviations}

ADE : Adverse drug event

BAU : Beirut Arab University

CCAPP: Canadian Council for Accreditation of Pharmacy Programs

DG : Development goals

FIP : International Pharmaceutical Federation

IPE : Interprofessional education

\author{
LAU : Lebanese American University \\ LIU : Lebanese International University \\ LU : Lebanese University
}

MEHE : Ministry of Education and Higher Education

$\mathrm{MOPH}$ : Ministry of Public Health

NGO : Non-governmental organizations

NSSF : National Social Security Funds

OPL : Order of Pharmacists of Lebanon

$\mathrm{P} \quad$ : Practice

$\mathrm{S}$ : Science

UN : United Nations

USJ : Saint-Joseph University

W : Workforce/education

WHO : World Health Organization

\section{References}

Aburas, W., \& Alshammari, T.M. (2020). Pharmacists' roles in emergency and disasters: COVID-19 as an example. Saudi Pharmaceutical Journal, 28(12), 1797-1816. https://doi.org/10.1016/j.jsps.2020.11.006

Akel, M., Ramia, E., Hajj, A., Hallit, S., Lahoud, N., Zaytoun, A., et al. (2019). Medication safety spontaneous reporting system: The Lebanese Order of Pharmacists initiative. Bulletin of Faculty of Pharmacy, Cairo University, 57(1), 66-81

Al-Hajje, A., Atoui, F., Awada, S., Rachidi, S., Zein, S., \& Salameh, P. (2012). Drug-related problems identified by clinical pharmacist's students and pharmacist's interventions. Annales pharmaceutiques françaises, 70(3), 169-176. https://doi.org/10.1016/j.pharma.2012.02.004

Al-Hajje, A., Awada, S., Rachidi, S., Chahine, N., Azar, R., Zein, S., et al. (2012). Medication prescribing errors: data from seven Lebanese hospitals. Le Journal medical libanais. The Lebanese medical journal, 60(1), 37-44

Alameddine, M., Bou Karroum, K., \& Hijazi, M.A. (2019). Upscaling the pharmacy profession in Lebanon: workforce distribution and key improvement opportunities. Human resources for health, 17(1), 47. https://doi.org/10.1186/s12960-019-0386-0

Alomi, Y. (2017). New pharmacy model for vision 2030 in Saudi Arabia. Journal of Pharmacy Practice and Community Medicine, 3(3), 194-196. https://doi.org/10.5530/jppcm.2017.3.40

Arcenciel. (2014). Guide of the healthcare waste management. Available at: http://www.databank.com.lb/docs/Guide\%20of\%20Healthc are\%20Waste\%20Management\%20in\%20Lebanon\%202014 \%20Arcenciel.pdf

Badejo, O., Sagay, H., Abimbola, S., \& Van Belle, S. (2020). Confronting power in low places: historical analysis of medical dominance and role-boundary negotiation between health professions in Nigeria. BMJ Global Health, 5(9). https://doi.org/10.1136/bmjgh-2020-003349

Badro, D. A., Sacre, H., Hallit, S., Amhaz, A., \& Salameh, P. (2020). Good pharmacy practice assessment among community pharmacies in Lebanon. Pharmacy Practice 
(Granada),

18(1),

https://doi.org/10.18549/PharmPract.2020.1.1745

1745.

Beirut Arab University. (2020a). Accreditation. Available at: https://www.bau.edu.lb/Pharmacy/Accreditation

Beirut Arab University. (2020b). Interprofessional Education. Available at: https://www.bau.edu.lb/Interprofessionaleducation

Blominvest Bank. (2018). Lebanon's Pharmaceutical Drugs Industry: A Diagnosis \& Prescribed Solutions. Available at: https://blog.blominvestbank.com/28022/lebanonspharmaceutical-drugs-industry-diagnosis-prescribedsolutions/

Bou Serhal, R., Salameh, P., Wakim, N., Issa, C., Kassem, B., Abou Jaoude, L., et al. (2018). A new Lebanese medication adherence scale: validation in Lebanese hypertensive adults. International journal of hypertension, 2018. https://doi.org/10.1155/2018/3934296

Braithwaite, J., Mannion, R., Matsuyama, Y., Shekelle, P., Whittaker, S., Al-Adawi, S., et al. (2017). Accomplishing reform: successful case studies drawn from the health systems of 60 countries. International Journal for Quality in Health Care, 29(6), 880-886. https://doi.org/10.1093/intqhc/mzx122

Center for Educational Research and Development (CRDP). (2021). Digital Learning Platform. Available at: https://dl.crdp.org

Coccolini, F., Sartelli, M., Kluger, Y., Pikoulis, E., Karamagioli, E., Moore, E. E., et al. (2020). COVID-19 the showdown for mass casualty preparedness and management: the Cassandra Syndrome. World Journal of Emergency Surgery, 15(1), 26. https://doi.org/10.1186/s13017-020-00304-5

Dimassi, A., Iskandar, K., Matta, R., Lahoud, N., \& Hanna, P. (2018). Effect of Infection Prevention and Control Measures on the Length of Hospital Stay of Patients at Lebanese Hospitals. Journal of Infectious Diseases and Epidemiology, 4, 050. https://doi.org/10.23937/2474-3658/1510050

Domiati, S., Sacre, H., Lahoud, N., Sili, G., \& Salameh, P. (2018). Knowledge of and readiness for medication therapy management among community pharmacists in Lebanon. International Journal of Clinical Pharmacy, 40(5), 1165-1174. https://doi.org/10.1007/s11096-018-0666-0

Doocy, S., Paik, K. E., Lyles, E., Hei Tam, H., Fahed, Z., Winkler, E., et al. (2017). Guidelines and mHealth to Improve Quality of Hypertension and Type 2 Diabetes Care for Vulnerable Populations in Lebanon: Longitudinal Cohort Study. JMIR Mhealth Whealth, 5(10), e158. https://doi.org/10.2196/mhealth.7745

Fineberg, H.V. (2012). Shattuck Lecture. A successful and sustainable health system--how to get there from here. New England Journal of Medicine, 366(11), 1020-1027. https://doi.org/10.1056/NEJMsa1114777

Frenk, J., Chen, L., Bhutta, Z., Cohen, J., Crisp, N., Evans, T., et al. (2010). Health professionals for a new century: transforming education to strengthen health systems in an interdependent world. The Lancet, 376(9756), 1923-1958. https://doi.org/10.1016/S0140-6736(10)61854-5

Green, B.N., \& Johnson, C.D. (2015). Interprofessional collaboration in research, education, and clinical practice: working together for a better future. Journal of Chiropractic Education, 29(1), 1-10. https://doi.org/:10.7899/JCE-14-36

Hajj, A. (2018). Pharmacogenetics in Pain Management. Available https://www.usj.edu.lb/recherche/pdf/2018/ahaji.pdf

Hajj, A., Azzo, C., Hallit, S., Salameh, P., Sacre, H., Abdou, F., et al. (2021). Assessment of drug-prescribing perception and practice among dental care providers: a cross-sectional Lebanese study. Pharmacy Practice (Granada), 19(1), 2234. https://doi.org/10.18549/PharmPract.2021.1.2234

Hajj, A., Halepian, L., Osta, N.E., Chahine, G., Kattan, J., \& Rabbaa Khabbaz, L. (2017). OPRM1 c.118A>G Polymorphism and Duration of Morphine Treatment Associated with Morphine Doses and Quality-of-Life in Palliative Cancer Pain Settings. International Journal of Molecular Sciences, 18(4). https://doi.org/10.3390/ijms18040669

Hajj, A., Hallit, S., Azzo, C., Abdou, F., Akel, M., Sacre, H., et al. (2019). Assessment of knowledge, attitude and practice among community pharmacists towards dental care: A national cross sectional survey. Saudi Pharmaceutical Journal, 27(4), 475-483. https://doi.org/10.1016/j.jsps.2019.01.010

Hajj, A., Hallit, S., Ramia, E., Salameh, P., \& Order of Pharmacists Scientific Committee - Medication Safety, S. (2018). Medication safety knowledge, attitudes and practices among community pharmacists in Lebanon. Current Medical Research and Opinion, 34(1), 149-156. https://doi.org/10.1080/03007995.2017.1361916

Hajj, A., Hallit, S., Sacre, H., Akel, M., Zeenny, R. M., \& Salameh, P. (2021). Lebanese Pharmacy Core Competencies Framework: Tool Validation for Self-Declared Assessment. International Journal of Pharmacy Practice, Under revision

Hajj, A., Hallit, S., Sacre, H., \& Salameh, P. (2018). Pratique de la Pharmacie Clinique au Liban Pharmacie clinique et thérapeutique (5 ed., pp. 1135-1140.e1132): Elsevier Masson. https://doi.org/10.1016/b978-2-294-750779.00063-3

Hajj, A., Khabbaz, L., Laplanche, J.L., \& Peoc'h, K. (2013). Pharmacogenetics of opiates in clinical practice: the visible tip of the iceberg. Pharmacogenomics, 14(5), 575-585. https://doi.org/10.2217/pgs.13.13

Hajj, A., Obeid, S., Sahyoun, S., Haddad, C., Azar, J., Rabbaa Khabbaz, L., et al. (2019). Clinical and Genetic Factors Associated with Resistance to Treatment in Patients with Schizophrenia: A Case-Control Study. International Journal of Molecular Sciences, 20(19). https://doi.org/10.3390/ijms20194753

Hajj, A., Peoc'h, K., Laplanche, J.L., Jabbour, H., Naccache, N., Abou Zeid, H., et al. (2015). Genotyping test with clinical factors: better management of acute postoperative pain? International Journal of Molecular Sciences, 16(3), 62986311. https://doi.org/10.3390/ijms16036298

Hajj, A., Sacre, H., Hallit, S., Zeenny, R.M., Sili, G., \& Salameh, P. (2020). Prescription and dispensing guidelines in Lebanon: initiative of the Order of Pharmacists of Lebanon. Journal of pharmaceutical policy and practice, 13(1), 1-5. https://doi.org/10.1186/s40545-020-00273-9

Hallit, S., Abou Selwan, C., \& Salameh, P. (2020). Primary health care policy and vision for community pharmacy and 
pharmacists in Lebanon. Pharmacy Practice (Granada), 18(2), 2003. https://doi.org/10.18549/PharmPract.2020.2.2003

Hallit, S., Hajj, A., Sacre, H., Zeenny, R.M., Akel, M., Sili, G., et al. (2019). Emphasizing the Role of Pharmacist as a Researcher: The Lebanese Order of Pharmacists' Perspective. Journal of Research in Pharmacy Practice, 8(4), 229-230. https://doi.org/10.4103/jrpp.JRPP_19_7

Hallit, S., Hajj, A., Shuhaiber, P., Iskandar, K., Ramia, E., Sacre, H., et al. (2019). Medication safety knowledge, attitude, and practice among hospital pharmacists in Lebanon. Journal of Evaluation in Clinical Practice, 25(2), 323-339. https://doiorg./10.1111/jep.13082

Hallit, S., Sacre, H., Hajj, A., Sili, G., Zeenny, R. M., \& Salameh, P. (2019). Projecting the future size of the Lebanese pharmacy workforce: forecasts until the year 2050. International Journal of Pharmacy Practice, 27(6), 582-588. https://doi.org/10.1111/ijpp.12564

Hallit, S., Sacre, H., \& Salameh, P. (2019). Role of a professional organization in promoting and conducting research: the Lebanese Order of Pharmacists' experience. International Journal of Pharmacy Practice, 27(3), 330-331. https://doi.org/10.1111/ijpp.12517

Hallit, S., Sacre, H., Sarkis, H., Dalloul, N., Jaoude, C.A., Nahhas, Z., et al. (2019). Good Pharmacy Practice Standardized for Community Pharmacists: The Lebanese Order of Pharmacists Initiative. Journal of Pharmacy Practice and Research, 8(1), 29-32. https://doi.org/10.4103/jrpp.JRPP_18_96

Hallit, S., Sacre, H., Zeenny, R.M., Hajj, A., Sili, G., \& Salameh, P. (2019). Credentialing and Recognition of Pharmacy Specializations: The Lebanese Order of Pharmacists Initiative. ACCP International Clinical Pharmacist

Hallit, S., Tawil, S., Sacre, H., Rahme, C., Hajj, A., \& Salameh, P. (2020a). Lebanese pharmacists' confidence and selfperceptions of computer literacy: scale validation and correlates. Journal of Pharmaceutical Policy and Practice, 13, 44. https://doi.org/10.1186/s40545-020-00246-y

Hallit, S., Tawil, S., Sacre, H., Rahme, C., Hajj, A., \& Salameh, P. (2020b). Lebanese pharmacists' confidence and selfperceptions of computer literacy: scale validation and correlates. Journal of Pharmaceutical Policy and Practice, 13(1), 1-8. https://doi.org/10.1186/s40545-020-00246-y

Hallit, S., Zahreddine, L., Saleh, N., Shakaroun, S., \& Lahoud, N. (2020). Practice of parents and pharmacists regarding antibiotics use in pediatrics: A 2017 cross-sectional study in Lebanese community pharmacies. Journal of Evaluation in Clinical Practice, 26(1), 181-189. https://doi.org/10.1111/jep.13165

Hallit, S., Zeenny, R.M., Sili, G., \& Salameh, P. (2017). Situation analysis of community pharmacy owners in Lebanon. Pharmacy Practice (Granada), 15(1), 853. https://doi.org/10.18549/PharmPract.2017.01.853

Hallit, S., Zeidan, R.K., Saade, S., Hajj, A., Hallit, R., Akel, M., et al. (2020). Knowledge, Attitude and Practice of Lebanese Community Pharmacists toward Chronic Obstructive Pulmonary Disease. Journal of Epidemiology and Global Health, 10(1), 86-95.
Hashem, M. (2016). Using Social Media in Governance and Crisis Communication: Case Study of The Lebanese Garbage Crisis. Proceedings of the E-Leader Vienna 2016 Vienna University of Technology, 6-8

Haydar, S.M., Hallit, S.R., Hallit, R.R., Salameh, P.R., Faddoul, L.J., Chahine, B.A., et al. (2019). Adherence to international guidelines for the treatment of meningitis infections in Lebanon. Saudi Medical Journal, 40(3), 260-265. https://doi.org/10.15537/smj.2019.3.23965

Higher Education Council. Bahrain National Research Strategy 2014-2024. Available at: http://www.moedu.gov.bh/hec/UploadFiles/Bahrain\%20Na tional\%20Research\%20Strategy\%20-\%20Summary.pdf

Hobeika, E., Farhat, J., Saab, J., Hleihel, W., Azzi-Achkouty, S., Sili, G., et al. (2020). Are antibiotics substandard in Lebanon? Quantification of active pharmaceutical ingredients between brand and generics of selected antibiotics. BMC $\begin{array}{llll}\text { Pharmacology Toxicology, 21(1), } 15 . & \end{array}$ https://doi.org/10.1186/s40360-020-0390-y

Hobeika, E., Hallit, S., Sacre, H., Obeid, S., Hajj, A., \& Salameh, P. (2020). Factors associated with empathy among community pharmacists in Lebanon. Journal of Pharmaceutical Policy and Practice, 13, 32. https://doi.org/10.1186/s40545-020-00237-z

Husni, R., Atoui, R., Choucair, J., Moghnieh, R., Mokhbat, J., Tabbarah, Z., et al. (2017). The Lebanese Society of Infectious Diseases and Clinical Microbiology: Guidelines for the treatment of urinary tract infections. Le Journal medical libanais. The Lebanese medical journal, 65(4), 208-219

Ibrahim, L., Ibrahim, L., Hallit, S., Salameh, P., Sacre, H., Akel, M., et al. (2020). Validation of the Lebanese Medication Adherence Scale among Lebanese diabetic patients. International Journal of Clinical Pharmacy. https://doi.org/10.1007/s11096-020-01197-9

INSPECT-LB. (2021). Institut National de Santé Publique, d'Epidémiologie Clinique et Toxicologie. Available at: https://inspect-lb.org

International Pharmaceutical Federation. (2021a). FIP Development Goals. Available at: https://www.fip.org/fipdevelopment-goals

International Pharmaceutical Federation. (2021b). FIPWiSE: Women in Science and Education initiative. Available at: https://www.fip.org/fipwise\#Highlights

Iskandar, K., Hallit, S., Raad, E. B., Droubi, F., Layoun, N., \& Salameh, P. (2017). Community pharmacy in Lebanon: A societal perspective. Pharmacy Practice (Granada), 15(2), 893. https://doi.org/10.18549/PharmPract.2017.02.893

Kabbara, W.K., Meski, M.M., Ramadan, W.H., Maaliki, D.S., \& Salameh, P. (2018). Adherence to International Guidelines for the Treatment of Uncomplicated Urinary Tract Infections in Lebanon. Canadian Journal of Infectious Diseases and Medical Microbiology, 2018, 7404095. https://doi.org/10.1155/2018/7404095

Lebanese American University. (2021a). Interprofessional Education. Available at: https://pharmacy.lau.edu.lb/education/ipe/ 
Lebanese American University. (2021b). School of Pharmacy, Pharm.D. Program Accreditation. Available at: https://pharmacy.lau.edu.lb/about/accreditation.php

Lebanese Health Energy. (2018). Lebanese Health Energy First Annual Congress. Available at: http://www.lhe-leb.org

Lebanese International University. LIU's Bachelor of Pharmacy Program (BPharm) Accreditation Status. Available at: http://liu.edu.lb/ACPE EN.pdf

Lebanese International University. (2021). Home Page. Available at: http://liu.edu.lb/morelink/news.php

Lebanese University. (2018a). Accreditations. Available at: https://www.ul.edu.lb/lu/accreditations.aspx

Lebanese University. (2018b). Faculté de Santé Publique. Available at: https://www.ul.edu.lb/faculte/branches.aspx?facultyld=14 \&lang $=3$

Mansur, J. (2016). Medication safety systems and the important role of pharmacists. Drugs \& aging, 33(3), 213221. https://doi.org/10.1007/s40266-016-0358-1

Ministry for Education and Employment- Malta. (2020). National Research and Innovation Strategy 2020. Available at: $\quad$ https://mcst.gov.mt/wpcontent/uploads/2017/02/National-RI-Strategy-2020-June2014.pdf

Ministry of Public Health. (2014). Guidelines on Good Storage and Distribution Practices of Pharmaceutical Products. Available https://www.moph.gov.lb/userfiles/files/HealthCareSystem Pharmaceuticals/QualityAssuranceofPharmaceuticalProduc ts/Guidelines-GSDPLebanon(English).pdf

Ministry of Public Health. (2019). Revised Hospital Accreditation Standards in Lebanon- January 2019. Available at:

https://www.moph.gov.lb/en/Pages/3/20553/accreditation -standards-for-hospitals-in-lebanon-january-2019

Ministry of Public Health. (2021a). Drugs Ethical Standards. Available https://www.moph.gov.lb/en/view/4753/drugs-ethicalstandards-

Ministry of Public Health. (2021b). Laws and Regulations. Available https://www.moph.gov.lb/en/laws\#/Laws/view/19

Ministry of Public Health. (2021c). MediTrackPharmaceuticals 2D Barcode Project. Available at: https://www.moph.gov.lb/en/Pages/6/15089/meditrackpharmaceuticals-2d-barcode-project

Ministry of Public Health. (2021d). Pharmaceuticals. Available at: https://www.moph.gov.lb/en/Pages/3/3010/pharmaceutica $\underline{\text { Is }}$

Ministry of Public Health. (2021e). Pharmacovigilance System in Lebanon. Available at: https://www.moph.gov.lb/en/Drugs/index/0/44741/letter:E Lpage:4/sort:Drug.brand name/direction:ASC

Ministry of Public Health. (2021f). Primary Health care. Available

at:
https://www.moph.gov.lb/en/Pages/3/749/primary-health$\underline{\text { care }}$

Ministry of Public Health. (2021g). Quality \& Safety. Available https://www.moph.gov.lb/en/DynamicPages/index/4

Moghnieh, R., Mokhbat, J., Bizri, A., Matar, M., Yared, N., Jradeh, J., et al. (2020). The Lebanese Society of Infectious Diseases and Clinical Microbiology (LSIDCM) Guidelines for the Management of COVID19. Available at: https://www.moph.gov.lb/userfiles/files/News/LSIDCM.pdf

Mouhtadi, B. B., Alame, M. M., Malaeb, B., Hallit, S., Salameh, P., \& Malaeb, D. (2018). Physician-community pharmacist collaborative care in diabetes management: a pilot study. $J$ Drug Assess, 7(1), 61-65. https://doi.org/10.1080/21556660.2018.1535437

Noubani, A., Nasreddine, L., Sibai, A.M., Tamim, H., \& Isma'eel, H. (2018). Prevalence, Awareness, and Control of Hypertension in Greater Beirut Area, Lebanon. International Journal Hypertension, 2018, 5419861. https://doi.org/10.1155/2018/5419861

Order of Pharmacists of Lebanon. (2018a). OPL Deliverables: Summary of a Mandate (December 2015-November 2018). Available https://opl.org.lb/newdesign/pdf/OPL\%20Deliverables.pdf

Order of Pharmacists of Lebanon. (2018b). OPL Pharmacovigilance Workshop. Available at: https://www.oplelibrary.com/libraryDocs

Patidar, A., Vinchurkar, K., \& Balekar, N. (2018). Digitalisation in Pharmacy. International Journal of Research in Pharmacy and Pharmaceutical Sciences, 3(5), 37-43

Rahme, D., Lahoud, N., Sacre, H., Akel, M., Hallit, S., \& Salameh, P. (2020). Work fatigue among Lebanese community pharmacists: prevalence and correlates. Pharmacy Practice (Granada), 18(2), 1844. https://doi.org/10.18549/PharmPract.2020.2.1844

Ramia, E., Salameh, P., Btaiche, I.F., \& Saad, A.H. (2016). Mapping and assessment of personal and professional development skills in a pharmacy curriculum. BMC Medical Education, 16, 19. https://doi.org/10.1186/s12909-0160533-4

Ramia, E., Zeenny, R.M., Hallit, S., \& Salameh, P. (2021). A population-based study of self-reported adverse drug events among Lebanese outpatients. Scientific Reports, 11(1), 7921. https://doi.org/10.1038/s41598-021-87036-x

Ramia, E., Zeenny, R.M., Hallit, S., Salameh, P., \& Order of Pharmacists Scientific Committee - Medication Safety, S. (2017). Assessment of patients' knowledge and practices regarding their medication use and risks in Lebanon. International Journal of Clinical Pharmacy, 39(5), 1084-1094. https://doi.org/10.1007/s11096-017-0517-4

Rough, S. Pharmacy Strategic Vision, 2016-2019 - UW Health. Available

at: https://www.uwhealth.org/files/uwhealth/docs/pharmacy/ pharmacy-strategic-plan.pdf

Sacre, H., Hajj, A., Aoun, R., Hallit, S., Zeitoun, A., \& Salameh, P. (2020). Drug safety in Lebanon. In Y. Al-Worafi (Ed.), Drug Safety in Developing Countries (pp. 449-470): Academic 
Press. https://doi.org/10.1016/B978-0-12-819837-7.000339

Sacre, H., Hallit, S., Hajj, A., \& Salameh, P. (2020). Current Challenges and Perspectives of Pharmacy In Middle Eastern Countries. In L. Villadsen (Ed.), Pharmacists: Current Challenges and Perspectives. New York: Nova Science Publishers

Sacre, H., Hallit, S., Hajj, A., Zeenny, R.M., Akel, M., Raad, E., et al. (2020). Developing Core Competencies for Pharmacy Graduates: The Lebanese Experience. Journal of Pharmacy Practice, https://doi.org/10.1177/0897190020966195 897190020966195.

Sacre, H., Hallit, S., Hajj, A., Zeenny, R.M., Raad, E., Akel, M., et al. (2020). Upgrading pharmacy education to produce practice-ready pharmacists in Lebanon. Pharmacy Education, 20(1), 1-16. https://doi.org/10.46542/pe.2020.201.379394

Sacre, H., Hallit, S., Hajj, A., Zeenny, R.M., Sili, G., \& Salameh, P. (2019). The pharmacy profession in a developing country: Challenges and suggested governance solutions in Lebanon. Journal of Research in Pharmacy Practice, 8(2), 39. https://doi.org/10.4103/jrpp.JRPP_19_5

Sacre, H., Obeid, S., Choueiry, G., Hobeika, E., Farah, R., Hajj, A., et al. (2019). Factors associated with quality of life among community pharmacists in Lebanon: results of a crosssectional study. Pharmacy Practice (Granada), 17(4), 1613. https://doi.org/10.18549/PharmPract.2019.4.1613

Sacre, H., Tawil, S., Hallit, S., Hajj, A., Sili, G., \& Salameh, P. (2019). Attitudes of Lebanese pharmacists towards online and live continuing education sessions. Pharmacy Practice (Granada), 17(2), 1438. https://doi.org/10.18549/PharmPract.2019.2.1438

Sacre, H., Tawil, S., Hallit, S., Sili, G., \& Salameh, P. (2019). Mandatory continuing education for pharmacists in a developing country: assessment of a three-year cycle. Pharmacy Practice (Granada), 17(3), 1545. https://doi.org/10.18549/PharmPract.2019.3.1545

Salameh, P., Sacre, H., Hallit, S., \& Hajj, A. (2017). Antibiotic resistance in Lebanon. Available at: http://resistancecontrol.info/2017/antibiotic-resistance-inlebanon/

Sholy, L., \& Saliba, C. (2018). Public awareness, experiences and views about counterfeit medicines in Lebanon. Journal of Pharmaceutical Health Services Research, 9(2), 161-169. https://doi.org/10.1111/jphs.12223

Suter, E., Oelke, N.D., Adair, C.E., \& Armitage, G.D. (2009). Ten key principles for successful health systems integration. Healthc $Q$, 13 Spec No, 16-23. https://doi.org/10.12927/hcq.2009.21092

Tawil, S., Hallit, S., Sacre, H., Hajj, A., \& Salameh, P. (2020). Pharmacists and continuing education: a cross-sectional observational study of value and motivation. Int J Pharmacy Practice, 28(4), 380-389. https://doi.org/10.1111/ijpp.12616

The Order of Pharmacists of Lebanon Scientific Committee. (2018). Health Promotion Counseling Tips. Available at: https://opl.org.lb/newdesign/pdf/Health\%20Promotion\%20 Booklet.pdf

Thibault, G. (2013). Reforming health professions education will require culture change and closer ties between classroom and practice. Health Affairs, 32(11), 1928-1932. https://doi.org/10.1377/hlthaff.2013.0827

Toma, A., \& Crişan, O. (2018). Green pharmacy-a narrative review. Clujul Medical, 91(4), 391. https://doi.org/10.15386/cjmed-1129

Université Saint-Joseph. Laboratoire de Toxicologie et Centre Anti-Poison. Available at: https://www.usj.edu.lb/sosdrogues/files/aide ecoute labotoxico.html

Université Saint-Joseph. (2014). Les formations, les séminaires et les colloques. Available at: https://usj.edu.lb/fc/dipl.htm?cursus=1546

Université Saint-Joseph. (2021). Management de la Valeur. Available https://www.usj.edu.lb/inst/matieres.php?id=27457\&code= 008MGVAM3

World Health Organization. (2010). Key components of a well functioning health system. Available at: https://www.who.int/healthsystems/publications/hss key/ en/

Yaacoub, S.G., Koyess, V., Lahoud, N., Rahme, D., Francis, N., Saleh, N., et al. (2019). Antibiotic prescribing for acute uncomplicated cystitis in Lebanese community pharmacies using a simulated patient. Pharmacy Practice (Granada), 17(4), 1604.

https://doi.org/10.18549/PharmPract.2019.4.1604

Zahreddine, L., Hallit, S., Shakaroun, S., Al-Hajje, A., Awada, S., \& Lahoud, N. (2018). Knowledge of pharmacists and parents towards antibiotic use in pediatrics: a cross-sectional study in Lebanon. Pharmacy Practice (Granada), 16(3), 1194. https://doi.org/10.18549/PharmPract.2018.03.1194

Zeenny, R.M., Akel, M., Hajj, A., Sacre, H., Hallit, S., \& Salameh, P. (2021). Lebanese Pharmacy Core Competencies Framework: A Descriptive Assessment Among Practicing Pharmacists. Under Revision. Pharmacy Practice (Granada)

Zeenny, R.M., Ramia, E., Akiki, Y., Hallit, S., \& Salameh, P. (2020). Assessing knowledge, attitude, practice, and preparedness of hospital pharmacists in Lebanon towards COVID-19 pandemic: a cross-sectional study. Journal of Pharmaceutical Policy and Practice, 13, 54 http://doi.org/10.1186/s40545-020-00266-8

Zeidan, R.K., Hallit, S., Zeenny, R. M., \& Salameh, P. (2019). Lebanese community-based pharmacists' interest, practice, knowledge, and barriers towards pharmacy practice research: A cross-sectional study. Saudi Pharmaceutical Journal, 27(4), 550-557. https:doi.org/10.1016/j.jsps.2019.02.002

Zeitoun, A., Sacre, H., Hallit, S., Zeenny, R.M., Sili, G., \& Salameh, P. (2020). Clinical preceptor competencies for a better pharmacy education: a suggested framework for Lebanon. Journal of Pharmaceutical Policy and Practice, 13, 21. https://doi.org/10.1186/s40545-020-00217-3 